\title{
Emmanuel Roblès et l'hispanité en Oranie
}

Paris, L'Harmattan, collection « Espaces littéraires », 2012

Hervé Sanson

\section{(2) OpenEdition}

Journals

Édition électronique

URL : https://journals.openedition.org/coma/248

DOI : $10.4000 /$ coma.248

ISSN : 2275-1742

\section{Éditeur}

Institut des textes \& manuscrits modernes (ITEM)

\section{Référence électronique}

Hervé Sanson, «Emmanuel Roblès et l'hispanité en Oranie », Continents manuscrits [En ligne], Comptes rendus de parutions, mis en ligne le 22 avril 2014, consulté le 20 janvier 2023. URL : http:// journals.openedition.org/coma/248; DOI : https://doi.org/10.4000/coma.248

Ce document a été généré automatiquement le 20 janvier 2023. 


\section{Emmanuel Roblès et l'hispanité en Oranie}

Paris, L'Harmattan, collection « Espaces littéraires », 2012

Hervé Sanson

\section{RÉFÉRENCE}

Emmanuel Roblès et l'hispanité en Oranie

Guy Dugas (dir.)Paris,

L'Harmattan, collection « Espaces littéraires », 2012

1 Le présent volume constitue les actes d'un colloque organisé par le Centre Culturel Français d'Oran et l'Université d'Oran-La Sénia en 2008, avec le concours de l'Institut de Recherche Intersite d'Études Culturelles de l'Université Montpellier III et du Fonds Roblès, dirigés tous deux par le professeur Guy Dugas.

2 Ces actes présentent la particularité d'une mise en valeur de l'arrière-fond socioculturel dans lequel a grandi le futur écrivain Emmanuel Roblès, ainsi que Pierre Rivas le met en relief dans sa contribution.

3 Ce n'est donc pas simple hommage d'universitaires à un écrivain français d'Algérie dont l'importance n'est plus à démontrer. Tel un millefeuille, l'ouvrage s'attèle à déplier l'hispanité d'Oranie - sur les plans historique, culturel, sociologique - depuis l'occupation espagnole au $\mathrm{xVI}^{\mathrm{e}}$ siècle jusqu'à la période coloniale française. Roblès est donc le "pré-texte" pour dresser ce panorama de l'hispanité dans toutes ses composantes, et établir des connexions avec d'illustres prédécesseurs, tel Cervantès, dont la parenté avec Roblès en termes de généalogie littéraire est analysée par Ahmed Abi-Ayad, tandis que Michel Moner analyse de façon magistrale l'inscription d'Oran et d'un imaginaire spécifique dans tel ou tel motif du Don Quijote.

4 Le «vacillement identitaire» ( $\mathrm{p}$. 107) de Roblès rejoint celui de certains contemporains : ainsi de Jean Sénac qui, soumis à une identité pied-noire bâtarde par essence, tout comme Roblès, partagea nombre de traits communs avec celui-ci. Les 
articles de Hamid Nacer-Khodja et Camille Tchéro évoquent remarquablement ces points de convergence entre les deux écrivains, que ce soit sur le plan de la critique littéraire partagée, l'évocation de la ville d'Oran, ou bien encore la représentation du père absent qui influera durablement sur leur existence.

Par suite, l'hispanité de Roblès lui-même n'est pas en reste, et Denise Brahimi s'essaie à définir concrètement ce que cette hispanité recouvre dans l'œuvre de l'écrivain, à quelles caractéristiques elle renvoie.

6 Un autre intérêt de cet ouvrage réside dans l'évocation des journaux d'alors, et de la collaboration de Roblès à leur préparation et à leur rédaction: ainsi, les pages culturelles d'Oran Républicain permirent à l'écrivain de nouer des relations fortes et durables. Guy Dugas, dans son article, conclut en ce sens :

[...] on constate que bien des écrivains espagnols avec lesquels il restera très lié ont participé aux pages spéciales d'Oran Républicain - journal qui, à ce titre, a constitué un maillon supplémentaire de cette châne d'amitiés que fut, autour d'événements majeurs, l'existence de cet écrivain. (p. 43).

7 La revue Simoun représente un autre lieu de rassemblement d'individualités fortes, de toutes origines ethniques, rassemblées dans une volonté humaniste et progressiste, autour de l'Algérie et de sa culture mais aussi de cette hispanité, ainsi que Michel Lambart l'explicite, mais les difficultés financières ainsi que la radicalisation des camps lors de la guerre d'indépendance algérienne auront raison de la pérennité de la revue, qui comptabilisera néanmoins trente-deux numéros.

La richesse du volume tient aussi à la présence en annexe d'extraits d'entretiens de James Kilker avec Roblès, apportant des précisions fort éclairantes sur sa formation scolaire, littéraire et politique.

9 Les propres souvenirs de la fille de l'écrivain, Jacqueline Roblès-Macek, égrènent les motifs de l'enfance, la naissance à l'écriture, les lectures formatrices, Oran et ses quartiers, ses paysages, l'absence du père, à partir de carnets de notes rédigés par Roblès, et de ses rédactions d'écolier, conservés au «fonds Roblès » à Limoges. Des extraits d'entretiens avec Georges-Albert Astre, Maurice Chavardès, Jean-Louis Depierris ou Kilker, déjà cité, viennent enrichir ces propos non convenus et émouvants.

Il faut noter aussi la belle contribution de l'écrivain oranais Yahia Belaskri, qui nous rappelle à quel point cet héritage hispanique doit être reconnu, préservé, mis en valeur en Algérie même.

11 L'œuvre littéraire de Roblès n'est pas en reste : son roman L'Action et sa pièce Montserrat sont respectivement évoquées par Fayçal Ben Saâdi et Bouziane Ben Achour dans leur dimension engagée et fraternelle.

Une section précieuse de ce volume, "Archives roblésiennes », nous présente le détail des fonds Roblès présents à la bibliothèque universitaire de Montpellier III ainsi qu'à la Bibliothèque Francophone Multimédia de Limoges : le premier préserve la bibliothèque ibérique et latino-américaine de Roblès; le second possède une importante correspondance adressée à l'écrivain par un grand nombre d'auteurs de langue espagnole.

13 Enfin, deux poèmes inédits d'Emmanuel Roblès lui-même, rédigés en espagnol, clôturent cet ensemble, certes disparate, mais qu'il est fort agréable de lire tant ses diverses entrées composent le portrait d'une Algérie hispanisante qui a, aussi, existé. 


\section{AUTEURS}

HERVÉ SANSON

Université d'Aachen (Allemagne) 